\title{
Research on Urban Park Management Problems and Countermeasures from the View of New Public Service Theory-Taking Chengdu as an Example
}

\author{
Xuewei Yu \\ School of Architecture, Southwest Minzu University, Chengdu, China \\ Email: 1515985562@qq.com
}

How to cite this paper: Yu, X.W. (2021) Research on Urban Park Management Problems and Countermeasures from the View of New Public Service Theory-Taking Chengdu as an Example. Open Access Library Journal, 8: e7811.

https://doi.org/10.4236/oalib.1107811

Received: July 31, 2021

Accepted: August 20, 2021

Published: August 23, 2021

Copyright $\odot 2021$ by author(s) and Open Access Library Inc.

This work is licensed under the Creative Commons Attribution International License (CC BY 4.0).

http://creativecommons.org/licenses/by/4.0/

(c) (i) Open Access

\begin{abstract}
With the development of China's economy and the improvement of people's living standards, urban parks, as an important place to meet the needs of residents' leisure life, have gradually become one of the important contents of urban construction, and are also one of the main contents of building urban landscape and urban ecosystem. The construction of urban parks in China started before the founding of the People's Republic of China. With the change of urban form, urban parks continued to develop. Especially after the reform and opening up, the construction of urban parks in China like bamboo shoots after a spring rain and landed in various cities. However, due to the further development of urban space construction, the management of urban parks has to face more and more challenges. Therefore, from the perspective of public service theory, this paper takes Chengdu urban parks as the research object, analyzes the problems existing in its management according to its current situation, and puts forward corresponding countermeasures and suggestions on the management problems of Chengdu urban parks.
\end{abstract}

\section{Subject Areas}

Urban Planning and Management in Ethnic Minority Areas

\section{Keywords}

City Parks, New Public Service Theory, Management, Chengdu

\section{Introduction}

As a part of urban construction, the urban park has always been a green space 
for residents to browse, watch, relax and carry out outdoor activities. Urban parks first appeared in the West in the 17th century, when it was considered a public space in urban space and could meet the growing spiritual and cultural demand for leisure and entertainment. And China's urban park construction and research started later than the west; its definition is mainly in the Chinese encyclopedia and the garden basic terminology standard that the urban park is used as public green space, can provide a place for the public to meet its exercise, tour landscape, and relaxation. China's urban park construction was proposed later, and its management mode is relatively single compared with western countries, mostly dominated by the government. In this context, with the rapid development of China's economy and the rapid advancement of urban construction, the management of urban parks has gradually surfaced and pays more and more attention to it.

The new public service theory is a new management model, with modern economics and private enterprise management theory as the theoretical basis, which is derived from various theoretical bases such as modern economics, public choice and transaction cost. In the academic circle, Dr. Robert B. Denhardt's research on new public service theory is the most widely used. In his book "New Public Service: Service Not the helm", he proposed the concept of "New Public Service Theory", and creatively pointed out that the function of government is the basic judgment of "service rather than the helm" [1]. The core of the theory lies in focusing on the role of "people".

As far as urban parks are concerned, introducing the new public service theory into the management of urban parks can make the management model of urban parks more sound.

Therefore, this paper takes the urban parks in Chengdu as an example, takes the new public service theory and puts forward the existing management problems of urban parks.

\section{The New Public Service Theory}

The new public service theory is to reshape the concept and value of administration from the perspective of market and economics, thus establishing a new set of administrative development framework. The new public service theory is a supplement and improvement to the new public management theory. It has many theoretical innovations. It points out that civil rights and public interests should be highly valued, and it puts forward a new theory suitable for the development of modern civil society. A new government management model is of great significance for guiding the practice of public services [2].

\section{Current Status of Chengdu Urban Park}

As one of the top ten ancient capitals of China, Chengdu is also one of the first famous historical and cultural cities in China. Because its special urban construction history-city site is not moved for 3000 years and the city name remains unchanged for 2500 years, so it has many famous historic sites and cul- 
tural landscapes. There are numerous urban parks in Chengdu, such as Wangjiang Tower Park and Tazishan Park, which are all indispensable and important venues for Chengdu residents' leisure and entertainment. As of 2016, there are more than 300 parks in Chengdu.

Since the expanded meeting of the Secretary General of China Park Association held in Guangzhou in 2001 proposed that urban parks, as the basic part of urban construction, should be open to the public, the upsurge of free opening of urban parks in China has been set off in big cities. Among them, after Chengdu took Xinhua Park as the first opening pilot, other parks in Chengdu have also joined the tide of free opening.

At present, Chengdu urban park management is mainly responsible by Chengdu Forestry Bureau, Garden Administration, Culture and Sports Tourism Bureau, Scenic Area Management Office and other departments. The large department parks in the city are open free of charge to meet the needs of citizens. The funds in the urban park including park construction and employee salary and welfare are mainly derived from government funding, while the garden maintenance costs are full government allocation and difference allocation. Its management system presents the mode of "government subject and vertical leadership", which is still the management system under the planned economy, which is because urban parks are mainly public institutions, in the management of it, the "official standard" thought is very obvious.

\section{Problems Existing in Urban Park Management in Chengdu}

\subsection{Public Facilities Are Old and Missing}

In Chengdu, there is also lack of old infrastructure in urban park management, such as the failure of signs in time, missing scenic spots and missing tourist project points. With the damage of trash cans, fruit skins, wrapping paper, mineral water bottles are discarded everywhere inside the park, which is extremely unfavorable to the park environment.

\subsection{Low Quality of Service}

This is mainly reflected in the lack of related services in Chengdu urban parks and the high similarity of service content. Now, Chengdu urban park services are mainly tea services, related entertainment facilities such as mahjong, newspapers, etc. No management and supervision of the relevant pets brought by tourists into the park may cause certain environmental problems, the lack of services for mother and baby, no relevant baby care; for tourists with certain physical risks, the lack of emergency services for emergencies [3]. In addition, most urban parks in Chengdu mainly provide tea, take photos and amusement parks, and the service projects are very similar and simple. On the one hand, the relevant management lacks the service, attaches great importance to management, too cold attitude towards tourists, and low patience. There are no relevant landscape and cultural interpreter, and the park is too easy to obtain relevant natural 
knowledge and history and culture of the park when playing. On the other hand, there are only a large number of security personnel in the park and few relevant management personnel. At the peak period of the weekend, the management is difficult to keep up with the pace, making the park order more disordered and affecting the quality of the park. In addition, in the construction of Chengdu urban parks, social organizations and citizens still lack the voice, and citizens' opinions are not easy to be adopted, and it is not easy to participate in the construction and development of urban parks, which is also one of the reasons for its low service quality.

\subsection{The Interior Greening Is Seriously Damaged}

As a tourist holy land, Chengdu has a large number of tourists and due to its high urban livability, the number of urban population is increasing year by year. Therefore, the flow of urban parks has also increased sharply [4]. For this reason, the too large number of tourists will seriously damage the relatively fragile greening facilities and preparation in the park. At the same time, if its supervision and report is not timely, the damage degree of the greening inside the park will be further intensified, which will further affect the overall visual effect of the park and the air quality level of the park.

\section{Chengdu Urban Park Management Countermeasures}

\subsection{We Will Improve the Supporting Infrastructure of Urban Parks}

On the one hand, we must rationally lay out the infrastructure. Because for urban parks, the construction of its infrastructure is directly related to the quality of service that residents can obtain and the convenience of living standards, so attention should be paid attention to its construction and improve the relevant leisure and entertainment equipment. Add tables, chairs and benches for visitors to rest and parking squares at various viewing points of the park, to provide visitors with a public place to facilitate mutual communication and meet leisure and sports needs; to prevent safety problems due to physical inconvenience, and replace damaged signs, display signs and other facilities.

At the same time, social forces will be introduced to participate in the construction of urban parks. Infrastructure serious damage, replace the main problems from its repair funds mainly rely on government investment, therefore, through the introduction of part of the social capital to the park construction, let it through private planting direct investment in urban park construction, the government in the late completion of its investment behavior, attract more people to participate in the park construction, let urban park construction become a thing, public welfare. Secondly, the public can also participate in the basic design, maintenance and management of the urban park. Through voluntary registration and other ways, nearby residents or students can participate in the management of the park through holidays. 


\subsection{We Will Improve the Service and Management Capacity of Urban Parks}

For the new public service theory, its core connotation is to play the role of "people", the person refers to a sense of belonging, can serve others, pursue public interests, but in the existing urban park management is mostly by the government directly formulate policies, management, construction, approval mode, therefore, to improve the urban park service management ability, is bound to make the park play its public nature, this is not only the service object, but also refers to a certain management level of public. From the resident level, we not only hope that the government can increase its investment in urban parks and enhance its service quality, on the other hand, but also do not want to increase its own tax burden because of this increased investment. However, the government, as an urban park capital investor, will inevitably have limited funds, which will lead to the lack of park infrastructure, management level and the decline of service quality. This inevitable contradiction eventually leads to reduced public trust in the government and questions about its ability [5]. Therefore, the government also faces the dilemma of increasing fiscal expenditure caused to increase the number of public goods in urban parks and the reduction of expenditure due to government financial constraints. Circulation continues, the development of urban parks is facing difficulties. Therefore, letting the public participate in the management of urban parks is one of the important solutions to this problem. Only by transforming the role and thinking about the problem from the other party's point of view can the urban park continue to develop.

Rich park service content and quality is also one of the important means to improve service management ability, management in the basic service project of the urban park, also need to increase the development of new service projects, according to the park itself has the humanities and natural resources to create flower park, sports park and other characteristic theme parks, and through the cooperation with social organizations, carry out activities, further improve the park related leisure and entertainment function, to create a park foreign brand. In order to improve the awareness of service of urban park managers, they can be punished by supervising the destruction of facilities and occupying equipment to a certain extent, and through the star rating of residents to change the service attitude and concept of managers. For the phenomenon of blind appreciation and play, the park explanation service team should be built to train a number of plants and historical and cultural backgrounds in the park at the beginning of construction, allowing them to explain the characteristic scenic spots in the park, so that tourists can influence the culture and interpret the park concept in the process of appreciation.

\subsection{We Will Strengthen the Environmental Management of Urban Parks}

For the greening landscape inside urban parks, the corresponding greening 
maintenance standards and implementation rules will be issued to realize the refinement, standardization and standardization of park greening maintenance, so as to improve the level of park greening maintenance and management [6]. For different scenic spots of green landscape, should be equipped with the corresponding head, clear its responsibilities, unified management, and carry out the corresponding monthly assessment and annual assessment, monthly assessment results into the annual assessment, the head of better landscape to give certain rewards, in order to mobilize their enthusiasm, promote the healthy development of green maintenance work.

For the cleaning problems in the park, the corresponding health inspection, supervision, management and assessment system should be formulated, so that the management staff can check the health situation around the park every time to time, and make relevant records, timely feedback to the relevant cleaning personnel, so as to ensure that the internal environment of the park can be well clean.

In addition, park stakeholders can also be encouraged to participate in environmental management, whether it is tourists, residents, park related operators, etc., and they can more or less affect the environment of the park through various channels. Due to their different subjects, the environmental management should restrain the park from its common place, such as the establishment of the same values, cooperative supervision, benefit sharing, so that they can feel that their own interests are closely related to the park environment and spontaneously participate in the park environmental management [7].

\section{Conclusion}

City park is the external appearance of a city, but also a symbol of vitality and culture. For Chengdu, Chengdu Urban Park is an important component of its urban green space system, and has made contributions not to be ignored to the construction of Chengdu. With the development of the times and the progress of society, urban parks should adhere to their public welfare nature and truly serve the public. In terms of its management, it should be combined with the new public service theory, adhere to the concept of "people-oriented", play the value of urban parks as quasi-public goods, so that the government, the public and social organizations can participate in their management work, put themselves in others' shoes and change the concept. Only in this way can Chengdu City Park develop better. At the same time, the management of urban park is a long-term problem. As an important symbol of a city, the management of urban park has a long way to go. How to dig deep into the new public service theory and better combine it with the management of urban park is the problem that needs to be thought about next.

\section{Conflicts of Interest}

The author declares no conflicts of interest. 


\section{References}

[1] Wu, H. (2010) On the Construction of a Service-Oriented Government under the New Public Service Theory. Legal System and Society, No. 33, 170-171.

[2] Yang, G. (2009) Review and Enlightenment of New Public Administration and New Public Service Theory. Fuzhou Party School Journal, No. 5, 39-42.

[3] Xie, T. and Zhao, H. (2011) Enlightenment from New Public Management Theory to New Public Service Theory-On the Reform and Development of Public Service in China. Theory, No. 22, 47-48.

[4] Li, F. (2009) China City Park-Take Chengdu Park for Example. Guangxi University for Nationalities (Philosophy and Social Sciences Edition), No. S1, 24-25.

[5] Yin, F. (2007) Chengdu City Park. Sichuan Normal University, Chengdu.

[6] Yin, F. and Du, L. (2006) Urban Park-Take Chengdu Park Development as an Example. Chengdu University Journal: Social Sciences, No. 4, 66-68.

[7] Wang, X. and Hu, Z. (2006) New Public Service Theory. Science, Education Collection (Second Half of the Month), No. 4, 155-156. 